\title{
Fetal Transverse Cerebellar Diameter (TCD) Measurement for Gestational Age Prediction in the Second and Third Trimesters of Pregnancy
}

\author{
Khadija Rehman \\ Medical Imaging Doctor \\ Superior University Lahore, Pakistan \\ Mob: +92334-6772017Ｅmail: syedakhadija9014@gmail.com \\ Hira Naz \\ Medical Imaging Doctor \\ Superior University Lahore, Pakistan \\ Mob:+92334-7284706 Email: hnaz745@gmail.com \\ Sana Ali \\ Lecturer, Superior College Lahore, University Campus \\ 17-KM Raiwind Road, Kot Arain, Lahore, Pakistan \\ Mob: +92336-7567611 Email: Sanaali802@gmail.com \\ Dr. Tuba Tariq \\ MBBS, FCPS Radiologist, Chaudhary Muhammad Akram \& Research Hospital \\ 17-KM Raiwind Road, Kot Arain, Lahore, Pakistan \\ Mob: +9245-5754568 Email: tubatariq@,hotmail.com \\ Rana Muhammad Bakhtawar Khan Sajawal \\ Lecturer, Superior College Lahore, university Campus \\ 17-KM Raiwind Road, Kot Arain, Lahore, Pakistan \\ Mob:+92304-2040204_Email: bksajawal77@gmail.com \\ Rana Muhammad Athar Azeem Shams \\ Lecturer, Superior College Lahore, university Campus, \\ 17-KM Raiwind Road, Kot Arain, Lahore, Pakistan \\ Mob:+92334-6996693 Email: atharshams44@gmail.com \\ Hafiz Muhammad Rizwan \\ Lecturer, Superior College Lahore, university Campus, \\ 17-KM Raiwind Road, Kot Arain, Lahore, Pakistan \\ Mob: +92343-5135072 Email: $\underline{\text { dr.rzwaan@gmail.com }}$
}

\begin{abstract}
Background:

The purpose of this study was to see how accurate transverse cerebellar diameter (TCD) measurement is at predicting gestational age in normal fetuses. In the $2^{\text {nd }} \& 3^{\text {rd }}$ trimesters of pregnancy a range of sonographics fetal biometric characteristics can be utilized to determine gestational age. Other parameters, such as bi-parietal diameter and fetal length, are used to determine transcerebellar diameter.

Objective(s): To determine the predictability of GA estimated from fetal TCD assessed on ultrasonography in the $2^{\text {nd }}$ and $3^{\text {rd }}$ trimesters of pregnancy.

Methodology:

This was a cross-sectional study conducted at the Ch. Mohammad Akram teaching and research hospital on 84 pregnant healthy ladies with fetuses ranging in age from 18 to 45 years old. During the $2^{\text {nd }}$ and $3^{\text {rd }}$ trimesters of pregnancy a routine ultrasound scan was done. In additions to the standard biometric parameter the transcerebellar diameter was estimated.

Results: The TCD of 84 patients as a measure of gestational age in weeks. These were generated from data collected during the study and include mean and standard deviation TCD measurements of 84 participants ranging in gestational age from 14 to 40 weeks. The current research found a significant link between the GA of TCD and the GA of BPD and fetal length. The TCD $(\mathrm{mm})$ mean and standard deviations were $33.74 \pm 11.762$ respectively. The TCD gestational age mean and standard deviations were $28.160 \pm 6.7942$ respectively. Bi-
\end{abstract}


parietal diameter $(\mathrm{mm})$ has a mean and standard deviation of $68.24 \pm 18.503$. Bi-parietal diameter had a mean and standard deviation of $27.996 \pm 6.9099$ gestational age. The standard deviation and mean $50.32 \pm 16.265 \mathrm{~mm}$ Fetal length The mean and standard deviation of fetal length gestational age are 27.423 \pm 6.7625 . Different criteria such as transcerebellar diameter, biparietal diameter, and femur length, are used to establish the gestational age of the fetus in this cross-sectional analysis.

Conclusion(s):

The TCD is a set of accurate variables for assessing GA in pregnant women in the $2^{\text {nd }}$ and $3^{\text {rd }}$ trimesters.

Key words: Transcerebellar diameter; Gestational age; Fetal length ; Bi-parietal diameter.

DOI: $10.7176 / \mathrm{JHMN} / 93-08$

Publication date:September $30^{\text {th }} 2021$

\section{INTRODUCTION}

TCD is a modern parameter for deciding gestational age. The cerebellum has appeared in posterior cranial fossa surround thick petrous ridges and occipital bone which allows to endure extrinsic pressure deformation. USG can detect the fetal cerebellum as early as 10-11 weeks. [1] The cerebellum is usually dumb-bell-shape, in fetal sonographic view, with two cerebellar hemispheres attach centrally by triangular-shaped vermis. [2] TCD measured in millimeters during the second trimester and is numerical equivalent to gestational age weeks. [3]

The age and growth of the Fetus are essential in pregnancy planning management mainly for low birth weight babies. Pregnancies with low-birth-weight babies that are ultrasound screened and managed have a 60 percent lower mortality rate. Crown-rump length is using to determine fetal age and growth during the fifth to tenth weeks of pregnancy. After that, various measurements are using, involve the Biparietal of skull, femur length and abdominal circumference. The ability to determine the range of fetal growth is improving by taking multiple measurements of these parameters over time. These parameter have limitation clinical utility in determining gestational age in late pregnancy or determining fetal development in pregnancy with unknown due dates. They are explained by the fact that as gestational age progressed, biologic variability increased. The assessment abnormally fetal development serial ultrasound scanning determination in 3rd trimester is necessary suitable intervention and fetal surveillance.[4]

So, based on the results of our prospective case control study we discovered such TCD measurements is a very important parameter in assessment and calculation gestational age of fetus and that it is good and accurate than others fetal biometric measurement (HC; FL; AC; BPD) that commonly used in pregnant women with no medically problem and our study also reveal high accuracy. Other biometric parameters are greatly affected in clinical scenarios and obstetric conditions etiology false assessment and improper measurement of GA such as hypertensives pregnant women gestation with IUGR infants diabetics mother with macrosomic infants and infants with congenitally and obviously conclude that TCD is good biometric measurements both simple and complicated condition. Since the cerebellar trend of sonographically developing and natural growth is not disrupted or manipulated by these conditions, complicated pregnancies with medical disorders including hypertension, particularly when combined with macrosomics or IUGR infants and standardised morphologically and structural abnormalitie seen sonographically affect organ other than the cerebellum.[5]

Majority women in this geographical region were first identified in their late second and third trimesters. The majority of them are uneducated or from rural culture, and they are unable to remember their last menstrual cycle in order to perform fetal dating. It's difficult to rule out the possibility of intrauterine growth retardation and tiny for date fetuses in such situations. Just a few studies have shown that the sonographic parameter TCD is a good prediction fertilization age in $3^{\text {rd }}$ trimester pregnancy. The measurement of the cerebellum unaffected by the fetus growth reduction alternatively acceleration.[6]

In an aim to find a way assess GA some studies have used TCD parameter and the TCD/AC ratio. [7] TCD predicts gestational age between 22 and 28 weeks to be like 0-2 days, between 29 to 36 week to be like 05 days, and 37 week to be like a 9 days of actual fertilization. The normally gram prediction of fertilization age with a $94 \%$ exact rate pregnancy in the $3^{\text {rd }}$ trimester. In a 2010 study conducting in Pakistan, Khokhar (2012) comparing TCD value of 850 patient pregnancy in $2^{\text {nd }}$ and $3^{\text {rd }}$ trimester with those of Chavez Hill and Goldstein found no substantial differences up to 28 weeks of pregnancy, but significant differences in the latter part of the third trimester. In the $2^{\text {nd }}$ and $3^{\text {rd }}$ trimesters of pregnancy, evaluate the using of TCD as an independent parameter for GA determination. [8,9] 
Rationale of study TCD is the accurate parameter for the early detection gestational ages in pregnancy $2^{\text {nd }}$ and $3^{\text {rd }}$ trimester.

\section{Material \& Methods}

Material and Methodology

\section{Study Design:}

This was cross-sectional prospective analysis. In this study 84 pregnant ladies in $2^{\text {nd }}$ and $3^{\text {rd }}$ trimesters was observed.

Settings: Ch. Mohammad Akram teaching and research hospital.

Duration of Study: The study was done from 20 December 2020 to 20 March 2021.

Sample Size: $n=84$ pregnant women.

\section{Selection of Samples:}

\section{Inclusion Criteria:}

1. Maternal age from 18 to 45 years

2. 14 to 40 weeks of pregnancy

3. Regular menses and also known LMP

\section{Exclusion Criteria:}

Pregnant patients with medically problems like diabetes or high blood pressure, twin pregnancy and firsttrimester pregnancy as well as lady with an unexplained Last Menstrual Period.

Equipment(s) : ( Canon Xario 200)

\section{Statistical analysis}

Graphs, charts, and other graphics is created using Microsoft Word and Excel. . The association of each ultrasonographically calculated parameter such as FL, BPD and TCD with the GA the fetus in normal pregnancy was analysis.

\section{Ethical consideration:}

I was making sure that my research did not endanger any subjects, like medical ethics. Many of the patients signed the document informed consent form. All details and data gathered were kept private. Throughout the report, participants were stored securely. The topic was told that there are no risks or drawbacks to the study method. They were also advised that they might leave the study at a certain point during the research phase.

Variables include:

Bi-parietal Diameter

Fetal length

Transverse cerebellar diameter

\section{Data collection procedure:}

The aim of my research was to see how well the fetal transverse cerebellar diameter measurements can predict GA $2^{\text {nd }}$ and the $3^{\text {rd }}$ trimesters of pregnancy. Sample size was selected 84 which will be the fulfilling the eligibility criteria and I was definitely informed about the nature of study of selected population. They were allowed to properly read the consent form which was issued from the head of my department. The subjects were allowed either to fill the questionnaire or to withdraw at any point of fulfilling the questionnaire whereas, I will also be there to provide the guidelines if they need it. All information gathered during the analysis was kept private and stored on a server with a password. All data in paper format is held in locked cabinet.

\section{RESULTS}

The TCD of 84 patients as a measure of gestational age in weeks. These were generated from data collected during the study and include mean and standard deviation TCD measurements of 84 participants ranging in gestational age from 14 to 40 weeks. The current research found a significant link between the GA of TCD and the GA of BPD and fetal length. According to Table 1, The TCD $(\mathrm{mm})$ mean and standard deviations were 33.74 \pm 11.762 respectively. The TCD gestational age mean and standard deviations were $28.160 \pm 6.7942$ respectively. Bi-parietal diameter $(\mathrm{mm})$ has a mean and standard deviation of $68.24 \pm 18.503$. Bi-parietal 
diameter had a mean and standard deviation of $27.996 \pm 6.9099$ gestational age. The standard deviation and mean $50.32 \pm 16.265 \mathrm{~mm}$ Fetal length The mean and standard deviation of fetal length gestational age are $27.423 \pm 6.7625$. Different criteria, such as transcerebellar diameter, biparietal diameter, and femur length, are used to establish the gestational age of the fetus in this cross-sectional analysis. Transcerebellar diameter gestational age is compared to other variables. Table 2 Between GA of FL, GA of TCD, and GA of BPD, regression analysis was used to estimate gestational age. TCD is a dependent variable (mm). GA of FL, GA of TCD, GA of BPD are all predictors. Table 3 shows the link between TCD and each of the other factors using regression analysis. TCD has the best connection with the gestational age of all the variables assessed. Table 4 For the total study correlations were found between fetal TCD and GA (correlation coefficient). TCD is a dependent variable (mm). The scatter plot shows (Fig.1) a positives direct connection between the TCD gestational age and the TCD $(\mathrm{mm})$. Fetal length $(\mathrm{mm})$, biparietal diameter $(\mathrm{mm})$, gestational age of Fetal length, and GA of bi-parietal diameter all have a positive relationship with a GA of the TCD.

Table 1

\section{Statistics}

\begin{tabular}{|c|c|c|c|c|c|c|c|}
\hline & & $\mathrm{TCD}(\mathrm{mm})$ & GA of TCD & $\mathrm{BPD}(\mathrm{mm})$ & GA of BPD & $\mathrm{FL}(\mathrm{mm})$ & GA of FL \\
\hline \multirow[t]{2}{*}{$\bar{N}$} & Valid & 84 & 84 & 84 & 84 & 84 & 84 \\
\hline & Missing & 0 & 0 & 0 & 0 & 0 & 0 \\
\hline \multicolumn{2}{|l|}{ Mean } & 33.74 & 28.160 & 68.24 & 27.996 & 50.32 & 27.423 \\
\hline \multicolumn{2}{|c|}{ Std. Deviation } & 11.762 & 6.7942 & 18.503 & 6.9099 & 16.265 & 6.7625 \\
\hline
\end{tabular}

Table 2 Regression analysis for estimating gestational age between GA of FL, GA of TCD, GA of BPD

Variables $2^{\text {nd }}$ and $3^{\text {rd }}$ trimester $^{\text {a }}$

\begin{tabular}{ll|l|l} 
Model & Variable Entered & $\begin{array}{l}\text { Variables } \\
\text { Removed }\end{array}$ & Method \\
\hline 1 & GA of FL, GA of & Enter \\
& $\begin{array}{l}\text { TCD, GA of } \\
\text { BPD }\end{array}$ & \\
\hline
\end{tabular}

a. Dependent Variables: TCD(mm)

b. All relevant variable given.

\begin{tabular}{|c|c|c|c|c|c|}
\hline \multicolumn{6}{|c|}{ Model Summary } \\
\hline Model & $\mathrm{R}$ & R Square & $\begin{array}{l}\text { Adjusted } \\
\text { Square }\end{array}$ & & $\begin{array}{l}\text { Std. Error of the } \\
\text { Estimates }\end{array}$ \\
\hline 1 & $.986^{\mathrm{a}}$ & .972 & .971 & & 2.007 \\
\hline
\end{tabular}

a. Predictor: (Constants), GA of FL, GA of TCD, GA of BPD

Table 3 Regression analysis was used to find out the correlation between TCD and each of the other parameters. ANOVA

\begin{tabular}{lll|l|l|l|l} 
Model & & Sum of Squares & df & Mean Square & F & Sig. \\
\hline \multirow{2}{*}{1} & Regression & 11159.846 & 3 & 3719.949 & 923.087 & $.000^{\mathrm{b}}$ \\
\cline { 2 - 8 } & Residual & 322.392 & 80 & 4.030 & & \\
\cline { 2 - 8 } & Total & 11482.238 & 83 & & & \\
\hline
\end{tabular}

a. Dependent Variables: TCD $(\mathrm{mm})$

b. Predictors: (Constants), GA of FL, GA of TCD, GA of BPD 
Table 4 For the entire group there was a link between fetal TCD and GA (correlation coefficients)

\section{Coefficient $^{\mathrm{a}}$}

\begin{tabular}{|c|c|c|c|c|c|c|}
\hline \multirow[b]{2}{*}{ Model } & & \multicolumn{2}{|c|}{ Unstandardized Coefficient } & \multirow{2}{*}{$\begin{array}{l}\text { Standardized } \\
\text { Coefficient } \\
\text { Beta }\end{array}$} & \multirow[b]{2}{*}{$\mathrm{t}$} & \multirow[b]{2}{*}{ Sig. } \\
\hline & & $\mathrm{B}$ & Std. Error & & & \\
\hline \multirow[t]{4}{*}{1} & (Constants) & -13.433 & .999 & & -13.452 & .000 \\
\hline & GA of TCD & .747 & .545 & .431 & 1.370 & .175 \\
\hline & GA of BPD & 1.295 & .563 & .761 & 2.301 & .024 \\
\hline & GA of FL & -.369 & .151 & -.212 & -2.445 & .017 \\
\hline
\end{tabular}

a. Dependent Variable: TCD $(\mathrm{mm})$

Scatter plot shows positive directs relation between GA of TCD. The TCD $(\mathrm{mm})$ and other given variables.
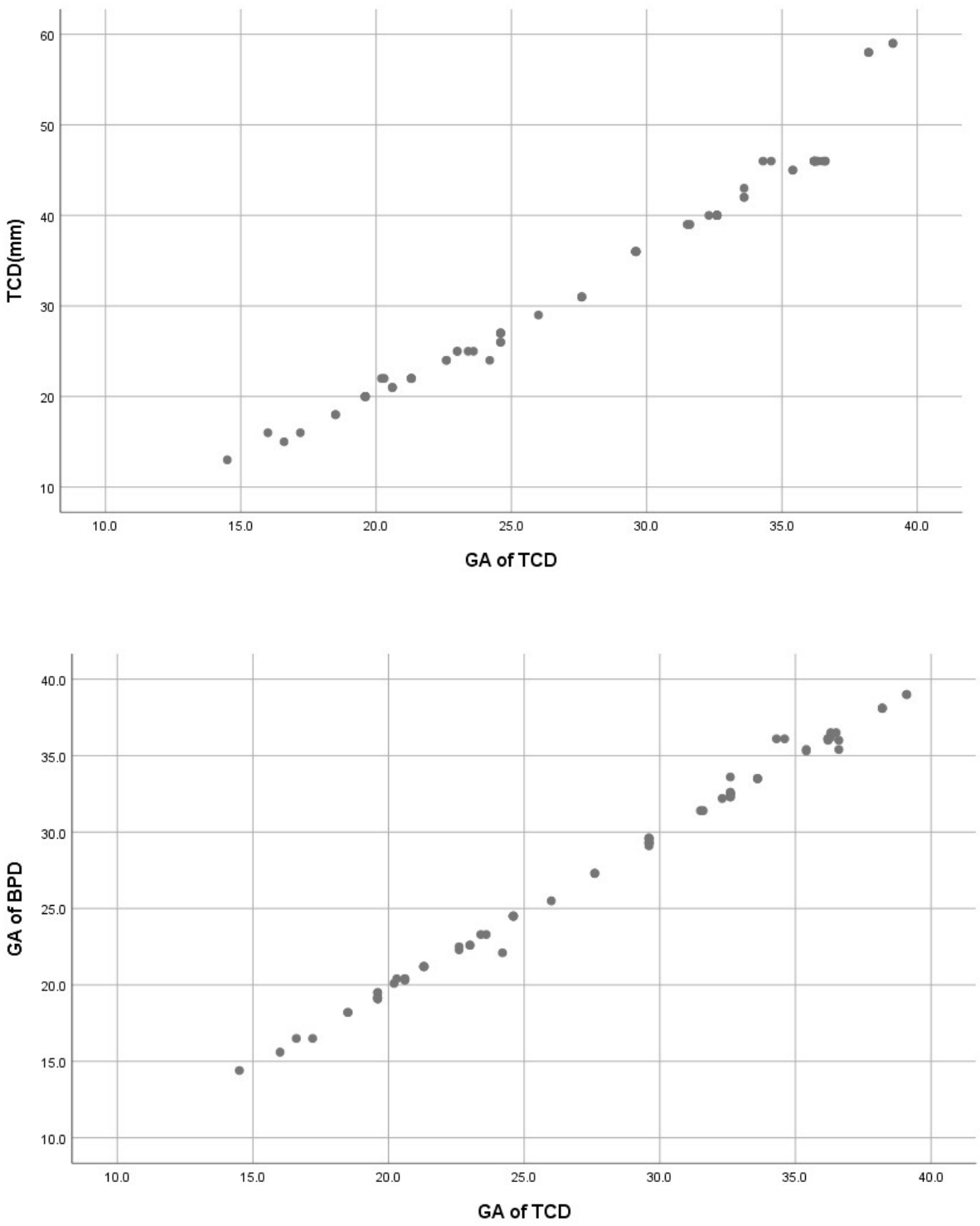


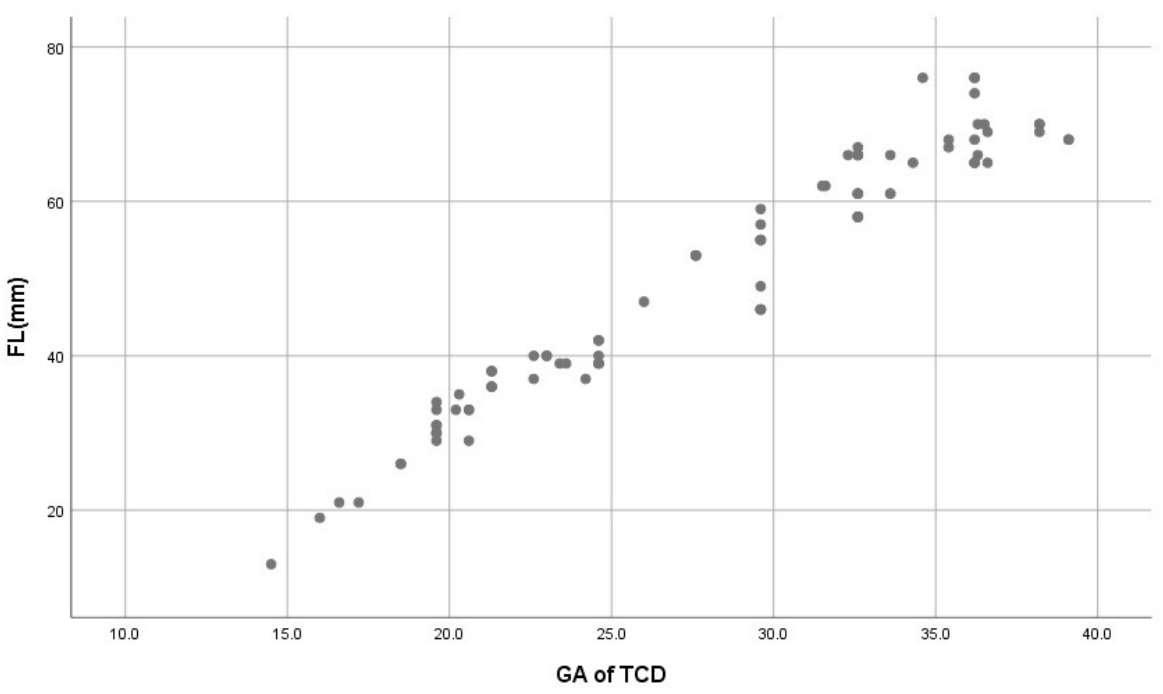

\section{DISCUSSION}

We found in our study the TCD accurate parameters for assessment GA 2nd \& 3rd trimesters of pregnancy have strong associations the Bi-parietal diameter, Fetal length. The TCD of 84 patients as a measure of gestational age in weeks. TCD measurements of 84 participants ranging in gestational age from 14 to 40 weeks. . Maternal age from 18 to 45 years TCD is a dependent variable $(\mathrm{mm})$. GA of FL, GA of TCD, GA of BPD are all predictors. . TCD has the best connection with the gestational age of all the variables assessed.Our TCD measurement has a similar relations with GA as previously publish nomogram in $2^{\text {nd }}$ and $3^{\text {rd }}$ trimester of pregnancy. Iram. S et al., the study that had been conducted for modern obstetrics could be built on the basis of predicting gestational age using prenatal sonographic parameters. The TCD serves as an exact estimate of fertilization Age in fetus the obey as benchmark across which other maternal parameter can be calculated. To see if GA, as described by prenatal TCD measured by ultrasound in the $2^{\text {nd }}$ to the $3^{\text {rd }}$ trimester of pregnancy could be predicted. The crosssectional study along with a sample size of 319 in good health pregnant women including healthy fetuses aged 18 to 40 years was performed for this reason at Gillani Ultrasound on Firozpur Road in Lahore. A normal ultrasound test was performed in the $2^{\text {nd }}$ and $3^{\text {rd }}$ trimesters. The study's conclusion was that TCD was a valid parameters for determining GA pregnancy in the $2^{\text {nd }}$ and $3^{\text {rd }}$ trimesters.

Some of the disparities between our nomogram results and those of established nomograms in the third trimester could be attributable to sample size. Our research sample was too small and As a result it does not accurately represent our entire population.TCD levels of the population Furthermore, racial and ethnic differences. Differences may also play a part in these disparities. In a 2010 study conducting in Pakistan, Khokhar (2012) comparing TCD value of 850 patient pregnancy in $2^{\text {nd }}$ and $3^{\text {rd }}$ trimester with those of Chavez Hill and Goldstein found no substantial differences up to 28 weeks of pregnancy, but significant differences in the latter part of the third trimester. In the $2^{\text {nd }}$ and $3^{\text {rd }}$ trimesters of pregnancy, evaluate the using of TCD as an independent parameter for GA determination.

\section{Conclusion}

TCD accurate indicator of GA in pregnancy second and third trimesters. It have a close relationship with GA, TCD, BPD, FL. The TCD is accurate parameters for determining GA in pregnancy $2^{\text {nd }}$ and $3^{\text {rd }}$ trimesters. Our TCD measurements in pregnancy second trimester have a close association with the gestational age as previously publish nomograms. Where others proven biometric indices are difficult to obtains it is a very useful tool.

\section{CONFLICT OF INTEREST/DISCLOSURE}

There is no conflict of interest in this research. 


\section{Reference}

1. Reddy RH, Prashanth K, Ajit M. Significance of foetal transcerebellar diameter in foetal biometry: a pilot study. Journal of clinical and diagnostic research: JCDR. 2017 Jun;11(6):TC01.

2. Uikey PA, Kedar KV, Khandale SN. Role of trans-cerebellar diameter in estimating gestational age in second and third trimester of pregnancy. Int. J. Reprod. Contracept. Obstet. Gynecol. 5, 3411-3415 (2016).

3. Joshi BR. Foetal transcerebellar diameter nomogram in Nepalese population. Journal. Of. Institute. Of. Medicine. 32, 19-23 (2010).

4. Bansal M, Bansal A, Jain S, Khare S, Ghai R. A study of correlation of transverse cerebellar diameter with gestational age in the normal \& growth restricted fetuses in Western Uttar Pradesh. PJSR. 2014;7(2):16-.

5. Alalfy M. The value of fetal trans cerebellar diameter in detecting GA in different fetal growth patterns in Egyptian fetuses. studies. 2017;7:9.

6. Asghar A, Rani M, Bala N. Determination of The Mean Fetal Biometrics and The Mean of Ratio of biometrics in 2nd and 3rd Trimester of Pregnancy in Correlation with Fetal Gestational Age: As a Predictive Biometric Parameters.

7. Naseem F, Ali S, Basit V and Fatima N (2014) Assessment of gestational age: a comparison between trans cerebellar diameter versus femur length on ultrasound in the third trimester of pregnancy. Professional Med J 21(2): 412-17.

8. Smith NC and Smith AP. (2006) Obstetric and Gynecological Ultrasound Made Easy. 2nd Edition. Churchill Livingston Elsevier;. 69-118 p.

9. Iram S, Gilani SA, Hassan ZU, Fatima M, Bacha R, Malik SS. Ultrasonographic Evaluation of the Fetal Transverse Cerebellar Diameter (TCD) Measurement for Prediction of

10. Gestational Age in 2nd and 3rd Trimesters of Pregnancy. International Journal of Applied Sciences and Biotechnology. 2018 Dec 28;6(4):379-85.

11. Nagesh R, Seetha Pramila VV, Shukla AK. Transverse Cerebellar Diameter-An Ultrasonographic Parameter For Estimation of Fetal Gestational Age. International journal of contemporary medical research. 2016;3(4).

12. Afshan A, Nadeem S, Asim SS. FETAL TRANSVERSE CEREBELLAR DIAMETER MEASUREMENT. The Professional Medical Journal. 2014;21(05):888-91.

13. Eze CU, Onwuzu QE, Nwadike IU. Sonographic reference values for fetal transverse cerebellar diameter in the second and third trimesters in a Nigerian population. Journal of Diagnostic Medical Sonography. 2017 May;33(3):174-81.

14. Malik R, Pandya VK, Shrivastava P. Gestational age estimation using transcerebellar diameter with grading of fetal cerebellum and evaluation of TCD/AC (Transcerebellar diameter/abdominal circumference) ratio as a gestational age independent parameter. Indian Journal of Radiology and imaging. 2003 Feb 1;13(1):95.

15. Mishra S, Ghatak S, Singh P, Agrawal D, Garg P. Transverse cerebellar diameter: a reliable predictor of gestational age. African Health Sciences. 2020 Dec 16;20(4):1927-32.

16. Bhimarao RM, Bhat V, Gowda PV. Efficacy of transcerebellar diameter/abdominal circumference versus head circumference/abdominal circumference in predicting asymmetric intrauterine growth retardation. Journal of clinical and diagnostic research: JCDR. 2015 Oct;9(10):TC01.

17. Holanda-Filho JA, Souza AI, Souza AS, Figueroa JN, Ferreira AL, Cabral-Filho JE. Fetal transverse cerebellar diameter measured by ultrasound does not differ between genders. Archives of gynecology and obstetrics. 2011 Aug;284(2):299-302.

18. Imamoglu EY, Gursoy T, Ovali F, Hayran M, Karatekin G. Nomograms of cerebellar vermis height and transverse cerebellar diameter in appropriate-for-gestational-age neonates. Early human development. 2013 Dec 1;89(12):919-23.

19. Mahmoud MZ, Mahmoud OA, Abdulla AA. Fetal transverse cerebellar diameter measurement for prediction of gestational age in pregnant Sudanese ladies. International Journal of Life Sciences and Medical Research. 2013 Jan;31(3):89-93. 
20. Agrawal C, Agrawal KK, Gandhi S. Assessment of fetal growth using the ratio of the transverse cerebellar diameter to abdominal circumference. International Journal of Gynecology \& Obstetrics. 2016 Oct 1;135(1):33-7.

21. Khan N. Role of Transverse Cerebellar Diameter in Diagnosis of Asymmetrical Fetal Growth Restriction. Journal of Rawalpindi Medical College. 2013 Dec 30;17(2):231-3.

22. Mandal SK, Ghosh SK, Roy S, Prakash B. Evaluation of Fetal Transcerebellar Diameter as a Sonological Parameter for the Estimation of Fetal Gestational Age in Comparison to Biparietal Diameter and Femur Length. age. 2019;6:7.

23. Araujo Junior E, Martins WP, Nardozza LM, Pires CR, Filho SM. Reference range of fetal transverse cerebellar diameter between 18 and 24 weeks of pregnancy in a Brazilian population. Journal of child neurology. 2015 Feb;30(2):250-3.

24. Singh A, Thukral CL, Singh J, Gupta K, Pahwa S. Role of Transcerebellar Diameter Measurement with Ultrasonography in Evaluation of Gestational age in Normal and Growth Restricted Fetuses. Asian Journal of Medical Radiological Research! Volume. 2018 Jul;6(2):8.

25. Fatima K, Shahid R, Virk A. Determination of mean fetal transcerebellar diameter as a predictive biometric parameter in third trimester of pregnancy in correlation with fetal gestational age. Pakistan Armed Forces Medical Journal. 2017 Feb 28;67(1):155-60.

26. Shinohara S, Okuda Y, Hirata S, Suzuki K. Predictive possibility of the transverse cerebellar diameter to abdominal circumference ratio for small-for-gestational-age fetus suspected as a cause of maternal placental syndromes: a retrospective cohort study. Hypertension in pregnancy. 2020 Apr 2;39(2):14551.

27. Goel P, Singla M, Ghal R, Jain S, Budhiraja V, Babu CR. Transverse cerebellar diameter-a marker for estimation of gestational age. Journal of anatomical society of India. 2010 Dec 1;59(2):158-61.

28. Gupta AD, Banerjee A, Rammurthy N, Revati P, Jose J, Karak P, Kumar A. Gestational age estimation using transcerebellar diameter with grading of fetal cerebellar growth. National Journal of Clinical Anatomy. 2012 Jul 1;1(3):115.

29. Vedpathak S, Jadhav D, Belsare S. ULTRASONOGRAPHIC STUDY OF TRANSVERSE DIAMETER OF FETAL CEREBELLUM AND LENGTH OF FEMUR AS MARKERS FOR ACCURATE ESTIMATION OF GESTATIONAL AGE. Int J Anat Res. 2020;8(1.3):7360-66.

30. Ahmed MA. Accuracy of fetal transcerebellar diameter nomogram in the prediction of gestational age in singleton gestation at the second and the third trimesters of singleton pregnancy. Journal of Evidence-Based Women's Health Journal Society. 2014 Nov 1;4(4):184-8.

31. Shah A, Shah MK. A correlation of trans cerebellar diameter by ultrasonography and gestational age in second and third trimester. Janaki Medical College Journal of Medical Science. 2018 Dec 22;6(2):55-9.

32. Kumar M, Kaushik R, Gupta D, Kumar L, Kumar P, Mukherjee S. Transverse Cerebellar Diameter as an Independent Predictor of Gestational Age in Normal and IUGR Pregnancies.

33. Rajendra TM. Evaluation of Fetal Transcerebellar Diameter as a Sonological Parameter for the Estimation of Fetal Gestational Age in Comparison to Fetal Biometry.

34. Desdicioglu R, Ipek A, Desdicioglu K, Gumus M, Yavuz AF. Determination of Fetal Transcerebellar Diameter Nomogram in the Second Trimester. Journal of Fetal Medicine. 2019 Dec;6(4):177-82.

35. Takano M, Hirata H, Kagawa Y, Murata S, Fujiwara M, Nakata M. Ratio of fetal anteroposterior to transverse cerebellar diameter for detection of the cerebellar hypoplasia in the second trimester and comparison with trisomy 18. Journal of Obstetrics and Gynaecology Research. 2015 Nov;41(11):175761.

36. Prasad VN, Dhakal V, Chhetri PK. Accuracy of transverse cerebellar diameter by ultrasonography in the evaluation gestational age of fetus. Journal of College of Medical Sciences-Nepal. 2017 Mar 10;13(1):225-8.

37. Hussain KA, Kadiyala S, Lakshmi AY, Hindumathi M. Fetal transcerebellar diameter to abdominal circumference ratio (TCD/AC) and to femur length ratio (TCD/FL) in the assessment of normal fetal growth. Journal of Dr. NTR University of Health Sciences. 2019 Jan 1;8(1):5. 
38. Alalfy M. The value of fetal trans cerebellar diameter in detecting GA in different fetal growth patterns in Egyptian fetuses. studies. 2017;7:9.

39. Khokhar SH. transcerebellar diameter in Pakistani population. European Congress of Radiology-ECR 2012.

40. Oloyede OA, Shorunmu TO, Adefuye PO, Abbey M. Foetal Transcerebellar Diameter (TCD) measurement between 18 and 23 weeks of pregnancy. Annals of Health Research. 2017 Jun 12;3(1):605 .

41. Jayaprakash N, Kumar A, PS SD. Determination Of Gestational Age In Third Trimester Using Foetal Transcerebellar Diameter And Assessment Of Foetal Growth Using Tcd/Ac Ratio.

42. Sersam LW, Findakly SB, Fleeh NH. Fetal Transcerebellar Diameter in Estimating Gestational Age in Third Trimester of Pregnancy. Journal of Research in Medical and Dental Science. 2019 Sep;7(5):60-6. 